\title{
Spiranoid Withanolides from Jaborosa odonelliana and Jaborosa runcinata
}

\author{
Adriana M. Cirigliano and Rosana I. Misico \\ Departamento de Química Orgánica, Facultad de Ciencias Exactas y Naturales, Universidad de \\ Buenos Aires, Pabellón 2, Ciudad Universitaria (C1428EGA) Buenos Aires, Argentina \\ Reprint requests to Dr. Adriana M. Cirigliano. Tel/Fax: (54-11) 4576-3346. \\ E-mail: adrianac@qo.fcen.uba.ar \\ Z. Naturforsch. 60b, 867 - 869 (2005); received December 28, 2004 \\ Two new spiranoid withanolides, $(20 R, 22 R, 23 R)-12 \beta, 17 \beta, 22$-trihydroxy-1-oxo-12,23-cycloergo- \\ sta-2,24-dien-26,23-olide (3) and (23R)-5 $\alpha, 6 \beta, 12 \beta, 21$-tetrahydroxy-1,22-dioxo-12,23-cycloergo- \\ sta-2,17,24-trien-26,23-olide (4) were isolated from plants of Jaborosa odonelliana and Jaborosa \\ runcinata, respectively. Compounds $\mathbf{3}$ and $\mathbf{4}$ were characterized by a combination of spectroscopic \\ methods (1D and 2D NMR, MS) and molecular modelling.
}

Key words: Jaborosa, Withanolides, Jaborosalactone

\section{Introduction}

The withanolides are a group of natural $\mathrm{C}_{28}$ steroidal lactones built on an intact or arranged ergostane framework that occurs mainly in plants of certain genera of Solanaceae. The first member of this group of compounds, withafarin A, was isolated from the well-known Indian medicinal plant, Withania somnifera [1] and its structure was fully elcidated by Lavie and coworkers in 1965 [2]. The withanolides exhibit a variety of biological activities as antifeedant, immunosuppressive and cancer chemoprevention activity [3].

Jaborosa Miers is a South American genus belonging to the Solanaceae family that comprises about 23 species, 11 of which are almost exclusively distributed in Argentina [4]. Previous studies on populations of $J$. odonelliana, J. runcinata and J. araucana, gave a group of withanolides with a spiranoid lactone ring in the side chain. The compounds isolated from J. odonelliana presented a 17,22-diol functionality and a $23 \mathrm{~S}$ stereochemistry at the spiranoid center (e.g. Jaborosalactone $\mathrm{P}, 1)$ [5], while those isolated from $J$. runcinata and $J$. araucana showed a 17(20)-ene-22-keto system and a $23 R$ stereochemistry (e.g. Jaborosalactone 2, 2) [6], in agreement with that found in $\mathbf{1}$.

Studies on cancer chemopreventive activity of withanolides as inducers of phase II detoxification enzymes indicated that the spiranoid withanolides jaborosalactone $\mathrm{P}$ and jaborosalactone 1 were promising agents in terms of inducing potency and low toxicity [7].

\section{Results and Discussion}

Jaborosalactone 24 (3) was isolated as a minor component from the aerial part of J. odonelliana. The HREIMS showed a molecular ion corresponding to the formula $\mathrm{C}_{28} \mathrm{H}_{36} \mathrm{O}_{6}$, whereas the EIMS showed peaks at $m / z 299(42)$ and 168 (31) corresponding to the cleavage between C-20-C-17 and C-23-C-12, distinctive for this type of structure [8]. ${ }^{1} \mathrm{H}$ and ${ }^{13} \mathrm{C} \mathrm{NMR}$ chemical shift values in jaborosalactone 24 (3) were closely related to those reported for jaborosalactone $\mathrm{P}$ (1) [5]. In the low-field end of the ${ }^{1} \mathrm{H}$ NMR spectrum signals at $\delta=5.81,6.73$ and 5.56 were assigned to H-2, H-3 and H-6, respectively, of a 1-oxo2,5-dienewithanolide. The typical pattern of the spiranoid arrangement was inferred from the resonances of carbons 23-28 (Table 1) and the low-field ${ }^{1} \mathrm{H}$ resonances of methyls 27 and 28 , observed as quartets $(J=1.0 \mathrm{~Hz})$ due to their mutual homoallylic coupling. Despite these similarities, detailed comparison of the NMR spectral data of $\mathbf{1}$ and $\mathbf{3}$ showed small but clear differences in the ${ }^{13} \mathrm{C}$ chemical shifts of the $\alpha, \beta$-unsaturated- $\gamma$-lactone ring, and a downfield shift of H-22. This indicated that the side chain of jaborosalactone 24 (3) had an arrangement different from that found in 1, possibly due to an inverted stereochemistry of the spiranoid center at C-23. The configuration at C-23 was confirmed to be $R$ by comparison of the NOESY spectra of $\mathbf{1}$ and $\mathbf{3}$. Thus, the correlation observed for the pair $\mathrm{H}-28 / \mathrm{H}-22$ in the NOESY spectrum 
Table $1 .{ }^{13} \mathrm{C}$ NMR spectral data of compounds 3 $(125.77 \mathrm{MHz})$ and $4(50.32 \mathrm{MHz})$ in $\mathrm{CDCl}_{3}$.

\begin{tabular}{rrrrrr}
\hline $\mathbf{C}$ & \multicolumn{1}{c}{$\mathbf{3}$} & $\mathbf{4}$ & $\mathbf{C}$ & $\mathbf{3}$ & $\mathbf{4}$ \\
\hline 1 & 203.8 & 203.3 & 2 & 127.6 & 128.8 \\
3 & 145.0 & 141.9 & 4 & 33.3 & 34.3 \\
5 & 135.4 & 79.7 & 6 & 124.9 & 73.8 \\
7 & 34.5 & 31.9 & 8 & 32.9 & 29.5 \\
9 & 39.9 & 38.3 & 10 & 50.0 & 51.6 \\
11 & 30.0 & 35.4 & 12 & 78.9 & 75.2 \\
13 & 50.8 & 48.9 & 14 & 43.6 & 46.4 \\
15 & 23.3 & 23.3 & 16 & 32.7 & 25.3 \\
17 & 83.5 & 165.6 & 18 & 10.7 & 14.8 \\
19 & 17.9 & 15.1 & 20 & 40.7 & 127.3 \\
21 & 11.8 & 58.2 & 22 & 69.0 & 193.5 \\
23 & 94.5 & 91.0 & 24 & 163.1 & 161.9 \\
25 & 126.7 & 128.1 & 26 & 171.6 & 173.4 \\
27 & 8.6 & 18.9 & 28 & 15.2 & 12.1 \\
\hline C multiplicities were determined from DEPT data. &
\end{tabular}

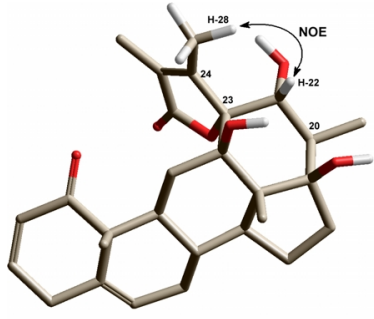

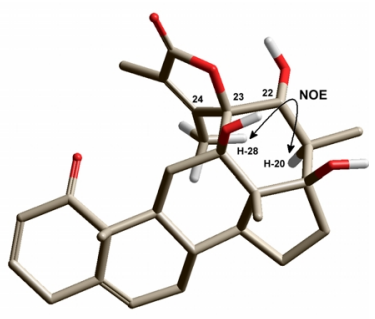

Fig. 1. AM1 calculated structures of a) jaborosalactone 24 (3) and b) jaborosalactone $\mathrm{P}(\mathbf{1})$, indicating relevant NOEs observed.

of 3 was only possible in the $23 R$ stereoisomer, while a correlation for the pair $\mathrm{H}-28 / \mathrm{H}-20$ was observed in the NOESY spectrum of $\mathbf{1}$ in agreement with the $23 \mathrm{~S}$ stereochemistry assigned to this compound (Fig. 1).

Jaborosalactone 25 (4), was isolated as a minor component from the aerial part of $J$. runcinata. The ${ }^{1} \mathrm{H}$ and ${ }^{13} \mathrm{C}$ NMR spectral data of $\mathbf{4}$ were very similar to those of jaborosalactone 2 (2) [6], however the absence of a singlet for $\mathrm{H}-21$ in the high-field end of the ${ }^{1} \mathrm{H}$ NMR spectrum and the appearance of an $\mathrm{AB}$ quartet at $4.21-4.33 \mathrm{ppm}$ indicated the presence of an isolated C-21 hydroxymethylene group. This functionality has been previously found in jaborosalactones 4 and 5 isolated from $J$. runcinata [6]. The ${ }^{13} \mathrm{C}$ NMR spectrum (Table 1) showed only four methyl groups that were coincident with C-18, C-19, C-27 and C-28 in 2. The methylene signal at $58.2 \mathrm{ppm}$ confirmed the presence of a hydroxyl group at C-21. The molecular ion was absent in the EIMS, but a peak at $\mathrm{m} / \mathrm{z} 480(1 \%)$ corresponding to the ion $\left[\mathrm{M}-\mathrm{H}_{2} \mathrm{O}\right]^{+}$was observed. A significant fragment was at $\mathrm{m} / \mathrm{z} 355$ (4\%), corresponding to the cleavage between $\mathrm{C}-23$ and $\mathrm{C}-22$ and the

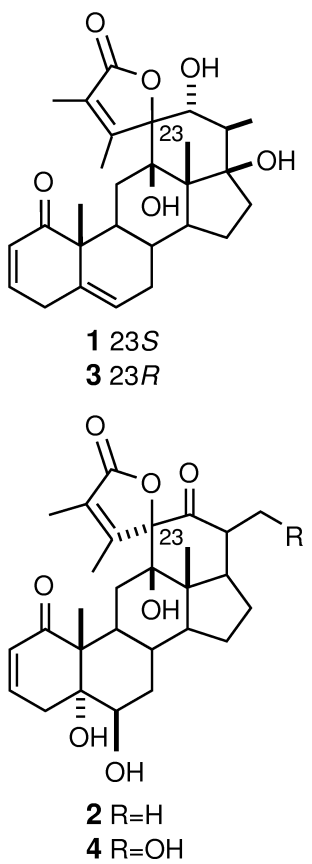

subsequent loss of the $\gamma$-lactone ring and $\mathrm{CO}$. The FABMS (glycerol) of jaborosalactone 25 (4) showed a $[\mathrm{M}+1]^{+}$ion at $\mathrm{m} / \mathrm{z}, 499$ consistent with the formula $\mathrm{C}_{28} \mathrm{H}_{34} \mathrm{O}_{8}$.

\section{Experimental Section}

General experimental procedures

${ }^{1} \mathrm{H}$ and ${ }^{13} \mathrm{C}$ NMR spectra were recorded on a Bruker AC$200 \mathrm{NMR}$ spectrometer at 200.13 and $50.32 \mathrm{MHz}$, respectively, or a Bruker AM-500 at 500.13 and $125.77 \mathrm{MHz}$, respectively. Multiplicity determinations (DEPT-135) and 2D spectra (COSY-45 and NOESY) were obtained using standard Bruker software. Chemical shifts are given in $(\delta)$ downfield from TMS as internal standard. EIMS were collected on a VG Trio- 2 mass spectrometer at $70 \mathrm{eV}$ by direct inlet; FABMS and HREIMS $(70 \mathrm{eV})$ were measured on a VG ZAB-BEQQ mass spectrometer. IR and UV spectra were measured on a Nicolet Magna 550 FT IR and a HewlettPackard 8451A spectrophotometer, respectively. AM1 calculations were performed with the MOPAC module in Chem3D 8.0 (Cambridge Soft). Melting points were taken on a FisherJohns apparatus and are uncorrected. HPLC separations were carried out on a YMC-Pack ODS-AQ column $(250 \times 10 \mathrm{~mm}$ ID) and a mixture of $\mathrm{MeOH}-\mathrm{H}_{2} \mathrm{O}$ (70:30) as eluant, with UV detection at $245 \mathrm{~nm}$. Vacuum liquid chromatography (VLC) and column flash chromatography were carried out on Kieselgel 60-G (Merck) and Kieselgel S 0.040-0.063 mm, respectively. TLC analysis was performed on silica gel 60 F254 (0.2 mm thick). 


\section{Plant material}

Whole J. runcinata plants were collected in March 1995 in El Jagüel, departamento Paraná, Entre Ríos Province, Argentina. Aerial parts of $J$. odonelliana were collected in April and December 1996 in Salta Province, Argentina. Voucher specimens of both species are deposited at the Museo Botánico, Universidad Nacional de Córdoba under No. CORD 248 (J. runcinata) and CORD No. 25540 (J. odonelliana).

\section{Extraction and isolation}

Leaves and stems $(1.15 \mathrm{~g})$ of $J$. odonelliana were extracted as previously described [8]. The residue obtained after evaporation of the combined extracts was initially fractionated by vacuum liquid chromatography using hexaneEtOAc mixtures of increasing polarity (100:0-0:100) as eluant.

The fraction eluted with hexane-EtOAc (40:60) was further fractionated by flash chromatography and purified by HPLC yielding jaborosalactone P (1) (176 mg) and jaborosalactone 24 (3) (3.4 mg).

The dried and pulverized aerial parts of $J$. runcinata $(935 \mathrm{mg}$ ) were extracted and fractionated as previously described [6]. The fraction eluted with hexane-EtOAc (20:80) was further purified by flash chromatography using mixtures of $\mathrm{CH}_{2} \mathrm{Cl}_{2}-\mathrm{MeOH}$ (100:5-100:10) yielding jaborosalactone 25 (4) (4.5 mg).

\section{Jaborosalactone 24 (3)}

Amorphous solid. - UV/vis $(\mathrm{MeOH}): \lambda_{\max }(\log \varepsilon)=$ $223 \mathrm{~nm}$ (3.07). - IR (dry film): $\tilde{v}=3458,2966,1747$, 1676, 1390, 1270, 1006, $728 \mathrm{~cm}^{-1} ;{ }^{1} \mathrm{H}$ NMR $(500.13 \mathrm{MHz}$, $\mathrm{CDCl}_{3}$, assignments based on ${ }^{1} \mathrm{H}^{-1} \mathrm{H}-\mathrm{COSY}$ ): $\delta=1.06$ (s,
$3 \mathrm{H}, 18-\mathrm{H}), 1.16$ (d, $J=6.4 \mathrm{~Hz}, 1 \mathrm{H}, 21-\mathrm{H}), 1.16$ (s, 3H, 19-H), 1.48 (m, 1H, 11 $\beta-\mathrm{H}), 1.80(\mathrm{~m}, 1 \mathrm{H}, 7 \alpha-\mathrm{H}), 1.99$ (q, $J=1.0 \mathrm{~Hz}, 3 \mathrm{H}, 27-\mathrm{H}), 2.02(\mathrm{~m}, 1 \mathrm{H}, 7 \beta-\mathrm{H}), 2.09(\mathrm{~m}, 1 \mathrm{H}$, $\mathrm{H}-20), 2.15$ (q, $J=1.0 \mathrm{~Hz}, 3 \mathrm{H}, 28-\mathrm{H}), 2.46$ (dd, $J=10.4$, $2.6 \mathrm{~Hz}, 1 \mathrm{H}, 11 \alpha-\mathrm{H}), 2.83(\mathrm{dd}, J=21.0,5.0 \mathrm{~Hz}, 1 \mathrm{H}, 4 \alpha-\mathrm{H})$, $3.24(\mathrm{dt}, J=21.0,2.5 \mathrm{~Hz}, 1 \mathrm{H}, 4 \beta-\mathrm{H}), 4.03(\mathrm{~d}, J=11.1 \mathrm{~Hz}$, $1 \mathrm{H}, 22-\mathrm{H}), 5.56(\mathrm{dd}, J=4.1,2.0 \mathrm{~Hz}, 1 \mathrm{H}, 6-\mathrm{H}), 5.81(\mathrm{dd}$, $J=10.0,2.5 \mathrm{~Hz}, 1 \mathrm{H}, 2-\mathrm{H}), 6.73$ (ddd, $J=10.0,5.0,2.5 \mathrm{~Hz}$, 1H, 3-H). $-{ }^{13} \mathrm{C}$ NMR (125.77 MHz) see Table 1. - MS (EI, $70 \mathrm{eV}): m / z(\%)=468(4)\left[\mathrm{M}^{+}\right], 450$ (2), $432(2)$, 299 (42), 283 (10), 265 (4), 168 (31), 107 (18), 97 (21), 43 (100); HREIMS $m / z=468.2512\left[\mathrm{M}^{+}\right]\left(\mathrm{C}_{28} \mathrm{H}_{36} \mathrm{O}_{6}\right.$, requires 468.2516).

\section{Jaborosalactone 25 (4)}

White solid. - Mp 253-255 ${ }^{\circ} \mathrm{C}$. - UV/vis $(\mathrm{MeOH})$ : $\lambda_{\max }(\log \varepsilon)=226 \mathrm{~nm}$ (3.25). - IR (dry film): $\tilde{v}=$ 3450, 1742, 1673, 1381, 1254, $1018 \mathrm{~cm}^{-1}$. - ${ }^{1} \mathrm{H}$ NMR (200.13 MHz, $\mathrm{CDCl}_{3}$, assignments based on ${ }^{1} \mathrm{H}-{ }^{1} \mathrm{H}-\mathrm{COSY}$ ): $\delta=1.14$ (s, 3H, 18-H), 1.26 (s, 3H, 19-H), 2.03 (q, $J=$ $1.0 \mathrm{~Hz}, 3 \mathrm{H}, 27-\mathrm{H}), 2.10(\mathrm{dd}, J=19.2,5.0 \mathrm{~Hz}, 1 \mathrm{H}, \mathrm{H}-4 \alpha)$, $2.25(\mathrm{q}, J=1.0 \mathrm{~Hz}, 3 \mathrm{H}, 28-\mathrm{H}), 2.64(\mathrm{~m}, 1 \mathrm{H}, 16-\mathrm{H}), 3.25$ (dt, $J=19.2,2.2 \mathrm{~Hz}, 1 \mathrm{H}, 4 \beta-\mathrm{H}), 3.66(\mathrm{t}, J=2.6 \mathrm{~Hz}, 1 \mathrm{H}$, 6-H), 4.21 (d, $J=12.2 \mathrm{~Hz}, 1 \mathrm{H}, 21 \mathrm{~b}-\mathrm{H}), 4.33(\mathrm{~d}, J=12.3 \mathrm{~Hz}$, $1 \mathrm{H}, 21 \mathrm{a}-\mathrm{H}), 5.82$ (dd, $J=10.1,2.2 \mathrm{~Hz}, 1 \mathrm{H}, 2-\mathrm{H}), 6.60$ (ddd, $J=10.1,5.0,2.2 \mathrm{~Hz}, 1 \mathrm{H}, 3-\mathrm{H}) .-{ }^{13} \mathrm{C}$ NMR $(50.32 \mathrm{MHz})$ see Table 1. - MS (EI, $70 \mathrm{eV}): m / z(\%)=480(1)\left[\mathrm{M}^{+}-\mathrm{H}_{2} \mathrm{O}\right](1)$, 355 (4), 107 (10), 97 (20), 43 (100); FABMS (glycerol) $\mathrm{m} / \mathrm{z}$ $499[\mathrm{M}+\mathrm{H}]^{+}$.

\section{Acknowledgements}

We thank the late Prof. A. T. Hunziker, Universidad Nacional de Córdoba, for identification of the plants. Financial support by CONICET (Argentina) and Universidad de Buenos Aires is gratefully acknowledged.
[1] P. A. Kurup, Current Sci. 25, 57 (1956).

[2] D. Lavie, E. Glotter, Y. Shvo, J. Chem. Soc. 7517 (1965).

[3] A. S. Anjaneyulu, D. S. Rao, P. W. Lequesne, Stud. Nat. Prod. Chem. 20, 135 (1998).

[4] A. T. Hunziker, G. Barboza, Flora, Fanerogámica Argentina 54, 1 (1998).

[5] E. S. Monteagudo, J. C. Oberti, E. G. Gros, G. Burton, Phytochemistry 29, 933 (1990).
[6] A.M. Cirigliano, A. S. Veleiro, G. M. Bonetto, J.C. Oberti, G. Burton, J. Nat. Prod. 59, 717.

[7] R.I. Misico, L.L. Song, A. S. Veleiro, A.M. Cirigliano, M.C. Tettamanzi, G. Burton, G. M. Bonetto, V. E. Nicotra, G. Silva, R. R. Gil, J. C. Oberti, A. D. Kinghorn, J. M. Pezzuto, J. Nat. Prod. 65, 677 (2002).

[8] A. M. Cirigliano, A. S. Veleiro, J. C. Oberti, G. Burton, J. Nat. Prod. 65, 1049 (2002). 